\title{
Searching and selecting the best evidence efficiently: a tool for clinicians, professors and dental students
}

Como buscar e selecionar a melhor evidência de forma eficiente: uma ferramenta para cirurgiões-dentistas, professores e alunos de odontologia

Paulo NADANOVSKY ${ }^{1}$

(iD) ORCID iD 0000-0003-3345-9873

Ana Paula Pires dos SANTOS 2

(iD) ORCID iD 0000-0001-5688-4747

\begin{abstract}
The aim of this article was to offer an efficient systematic search strategy appropriate for clinicians, professors and dental students, for when they have a question regarding the effectiveness of clinical intervention. We adapted the "6-5 System" proposed for Medicine in order to build a search strategy focused on oral health, which is speedy, easy to use and arrives at the appropriate evidence. With a focus on validity and search efficiency, the following searching sequence is proposed: critical abstracts of systematic reviews (SR) of randomized controlled trials (RCTS), SR of RCTS, critical abstracts of RCTS, and RCTs. These can be searched in the Cochrane library; evidence-based journals; websites and blogs; and in Pubmed using the tool Clinical Queries. This strategy can enhance the ability to quickly retrieve evidence that is important to dental education, clinical practice and delivery of oral health care. The adoption of strategies such as the one proposed in this paper is likely to increase evidence based dental practice.
\end{abstract}

Indexing terms: Education, dental. Evidence-based dentistry. Evidence-based practice.

\section{RESUMO}

O objetivo deste artigo foi apresentar uma estratégia de busca sistemática e eficiente, apropriada para cirurgiões-dentistas, professores e alunos de Odontologia, para ser utilizada quando eles tiverem dúvidas sobre a efetividade de uma intervenção clínica. O sistema proposto para a Medicina, chamado de "Sistema 6-S", foi adaptado para que uma estratégia de busca com foco na Odontologia fosse construída. Essa estratégia é fácil e rápida de usar e alcança a melhor evidência científica disponível. A sequência de busca proposta, com foco na validade da evidência e eficiência da busca, consiste em: resumos críticos de revisões sistemáticas (RS) de ensaios controlados randomizados (ECR), RS de ECR, resumos críticos de ECR e, por último, ECR. A busca por esses artigos pode ser feita na biblioteca Cochrane; em revistas de odontologia baseada em evidência; sites da Internet e blogs; e no Pubmed através da ferramenta "Clinical Queries". Essa estratégia pode aprimorar a habilidade de obter rapidamente evidência importante para informar a prática clínica, a educação em Odontologia e o cuidado em saúde bucal. A adoção de estratégias como a proposta neste artigo pode aumentar a prática da Odontologia Baseada em Evidência.

Termos de indexação: Educação em Odontologia. Odontologia baseada em evidências. Prática clínica baseada em evidências.

\section{INTRODUCTION}

Dental practice constantly faces clinical situations that demand choices. Information on how to make these choices can be obtained from different sources including journals, internet, conferences and discussions with colleagues. However, evidence-based choice partly depends on finding the best scientific information available, which will inevitably involve the selecting and reading of scientific texts. These are so abundant that when facing the same clinical doubt two clinicians or professors may select and read different texts and possibly get different answers. Or, they may obtain the same answer, but one more quickly than the other.

Researchers who are searching the literature to perform a systematic review are evidence producers, while those who are searching the literature to answer

\footnotetext{
${ }^{1}$ Fundação Oswaldo Cruz, Escola Nacional de Saúde Pública, Departamento de Epidemiologia. Rio de Janeiro, RJ, Brasil.

${ }^{2}$ Universidade do Estado do Rio de Janeiro, Faculdade de Odontologia, Programa de Pós-Graduação em Odontologia. Boulevard 28 de Setembro, 157, 20551-030, Vila Isabel, Rio de Janeiro, RJ, Brasil. Correspondência para / Correspondence to: APP SANTOS. E-mail: <ana.paulapires@uol.com.br>

$\boldsymbol{\nabla} \mathbf{\nabla} \boldsymbol{\nabla}$

Como citar este artigo / How to cite this article

Nadanovsky P, Santos APP. Searching and selecting the best evidence efficiently: a tool for clinicians, professors and dental students. RGO, Rev Gaúch Odontol. 2018;66(2):00-00. http://dx.doi.org/10.1590/1981-8637201800020000113423
} 
a specific clinical doubt are evidence consumers. Evidence producers need very sensitive search strategies that are exhaustive and time-consuming. On the other hand, evidence consumers need quick and efficient search strategies that are still valid. For years now, searching guides have been available that inform evidence producers [1]. However, despite of (or because of) the plethora of sources of scientific texts, no systematic way of searching and selecting the best available evidence has been proposed for evidence consumers in dentistry.

This paper offers a systematic search strategy for evidence consumers in dentistry so that dental students, professors and clinicians can quickly find evidence with a high probability of being valid.

\section{The rationale for the search strategy we are proposing}

When it comes to the effectiveness of interventions, evidence-consumers should look for experimental evidence, i.e., randomized controlled trial (RCT). This study design is the least vulnerable to methodological biases, thus it tends to provide valid results more likely than observational studies do. However, as all RCTs evaluating the same intervention have to be considered, evidence-consumers should give priority to systematic reviews (SR) of RCTs over a single RCT.

Despite providing the best currently available evidence of health interventions, reading SR can be a daunting task. Therefore, in order to be efficient and still select valid evidence, one should firstly look for evidence-based abstracts, or "pre-appraised" evidence, i.e., texts that have already been scrutinized by specialists. Whenever evidence-consumers lack the expertise or the time to critically appraise research evidence, they can look for answers in pre-appraised evidence resources. The $6-5$ System is a model that classifies knowledge into six categories: Systems: computerized decision support; Summaries: evidencebased textbooks; Synopses of syntheses: evidencebased journal abstracts; Syntheses: systematic reviews; Synopses of studies: evidence-based journal abstracts; Studies: original articles [2]. Other categorizations have also been proposed, which emphasizes the importance of providing summaries of all the knowledge about a particular topic [3].

We adapted these categorizations in order to propose a search strategy to be used in oral health. Our strategy suggests not only the sources that should be accessed, but also a sequence that should be followed, as there are two central pillars: validity of the evidence and efficiency of the search.

\section{The illustration and detailed description of the search strategy sequence}

The whole process can be summarized in four hierarchical steps (Figure):

$1^{\text {st }}$ step-Critical abstracts of systematic reviews of $R C T S$

$2^{\text {nd }}$ step- Systematic reviews of RCTs

$3^{\text {rd }}$ step-Critical abstracts of RCTS

$4^{\text {th }}$ step- $R C T s$

Evidence consumers should firstly try to find a critical abstract of a SR of RCTs on the specific clinical doubt. In case this type of publication or the answer to the doubt is not found, they should then try to find a SR of RCTs. When they find the answer in the first step, the process is finished. Thus, as a general rule of this tool, the finding of the answer in one step eliminates the need for the evidence consumers to carry through to the following steps. They should stop at the earliest step possible in order preserve the tool's efficiency.

\section{Where to find the publications in each step of the search strategy (Figure)}

We propose the following searching sequence:

\section{$1^{\text {st }}$ step) Critical abstracts of systematic reviews of RCTs}

\subsection{Database of Reviews of Effects (DARE)}

This database contains abstracts of quality assessed and critically appraised SR of health and social care interventions that are available in Cochrane Library (www.cochranelibrary.com) and in PubMed Health (www.ncbi.nlm.nih.gov/pubmedhealth). Bibliographic records were published on DARE until 31 March 2015. From this date on, the National Institute for Health Research Dissemination Centre at the University of Southampton, UK, took over this task from the University of York, UK, and has made available summaries of new research (www.dc.nihr.ac.uk).

\subsection{Evidence-based journal abstracts}

These journals select papers, including SR 
of RCTs, which were published in a wide range of sources. Explicit scientific merit criteria are applied and the clinical relevance and validity of the results are assessed. The selected reviews are then republished as abstracts followed by a specialist commentary. The aim is to provide readers with clear, comprehensive and easily digestible summaries of SR. In dentistry, there are two journals that fit these descriptions: Evidencebased Dentistry (www.nature.com/ebd) and Journal of Evidence-Based Dental Practice (www.jebdp.com).

\section{$2^{\text {nd }}$ step) Systematic reviews of RCTs}

\subsection{Cochrane Database of Systematic Reviews (CDSR)}

Cochrane Reviews are the leading resource for SR in healthcare and health policy; they are published in the CDSR, updated regularly and can be searched directly in the Cochrane library (www.cochranelibrary. com). To explore Cochrane Reviews readers can browse by topic or by Cochrane Review Group (CRG), such as the Oral Health Group. Each CRG is led by a coordinating editor(s) and an editorial team, who provide authors with methodological and editorial support, and manage the editorial and peer review processes. Information on how a Cochrane Review is performed can be found in the Cochrane Handbook (www. handbook.cochrane.org).

\subsection{Medline/Pubmed}

Systematic reviews published in dental journals should be searched in Medline, the U.S. National Library of Medicine ${ }^{\circledR}$ premier bibliographic database. Medline citations can be retrieved in Pubmed (http://www.ncbi. nlm.nih.gov/pubmed). In order to find SR in Medline/ Pubmed, one should use the Clinical Queries tool (http://www.ncbi.nlm.nih.gov/pubmed/clinical), i.e., online search filters designed to improve the retrieval of scientifically strong and clinically relevant articles from Medline and have been available in PubMed since 2000 [4]. Naive users, new clinicians or those less skilled at the assessment of research findings may derive more benefit from the Clinical Queries searches than skilled users of Pubmed [5]. The results of the searches using this tool will automatically display a column named "systematic reviews" where there will be citations for SR, meta-analyses, reviews of RCTs, evidence-based medicine, consensus development conferences, and guidelines.

\section{$3^{\text {rd }}$ step) Critical abstracts of RCTs}

The same sources described in item 1.2 can be assessed to search for critical abstracts of RCTs, as some of the papers published by these sources are reports of RCTs.

\section{$4^{\text {th }}$ step) RCTs}

\subsection{Cochrane Central Register of Controlled Trials (CENTRAL)}

CENTRAL is a comprehensive database that contains reports of RCTs, irrespective of language or date of publication. It is available at the Cochrane Library (www.cochranelibrary.com). Most records are taken from Medline and Embase, but there are records also derived from other published and unpublished sources. CENTRAL records include bibliographic details and a summary of the articles.

\subsection{Medline/Pubmed}

Evidence consumers can also search for RCTs in Medline/Pubmed using the Clinical Queries tool, as described in item 2.2. In this case, the clinical study category to be selected in the Clinical Queries tool is therapy. It is also possible to select the scope: broad, which is optimized for sensitivity, or narrow, which is optimized for specificity. One should initially try the filter optimized for specificity. Only when this option does not retrieve an appropriate publication, should the more sensitive filter be used.

\section{Additional sources}

In addition to the databases and journals described above there are other user-friendly sources that could be helpful. These are the following:

- The Dental ELF (www.thedentalelf.net). This is a daily blog highlighting evidence-based publications relevant to dental practice, including brief summaries of critically appraised SR and RCT.

- The American Dental Association EvidenceBased Dentistry Website - ADA-EBD (ebd.ada.org). This is a website that can be browsed by clinical topic and provides access to SR and to critical summaries of SR.

- The TRIP (Turning Research Into Practice) Database (www.tripdatabase.com). This is a database from a limited company that collates SR, RCT and critically appraised $S R$ and RCT from all the sources cited above. 


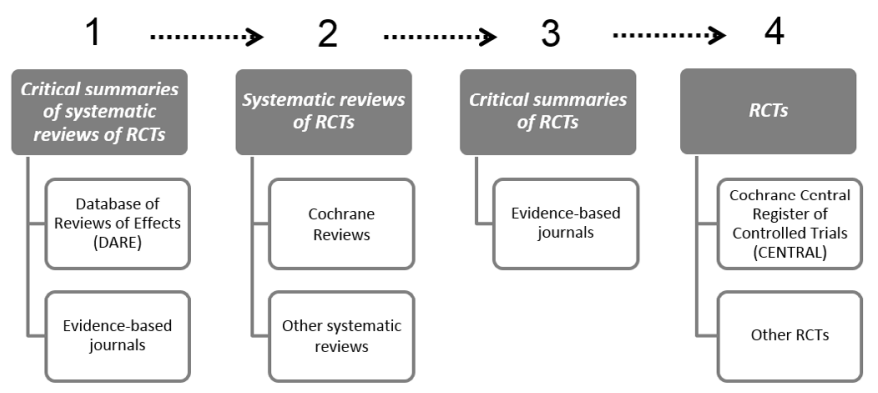

$R C T:$ Randomized controlled trial

A) Searching sequence|
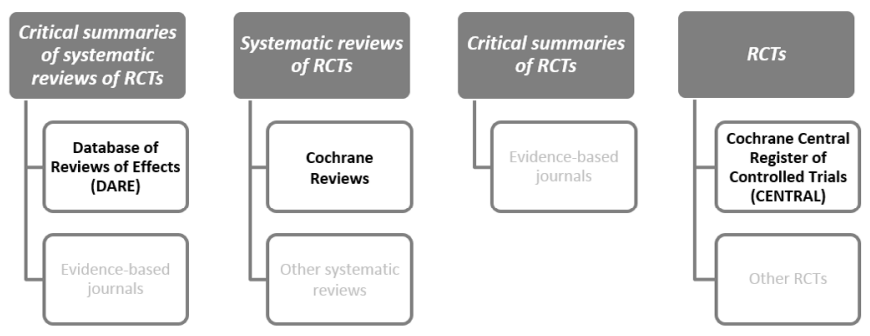

B)

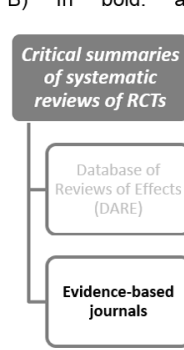

available at Cochrane
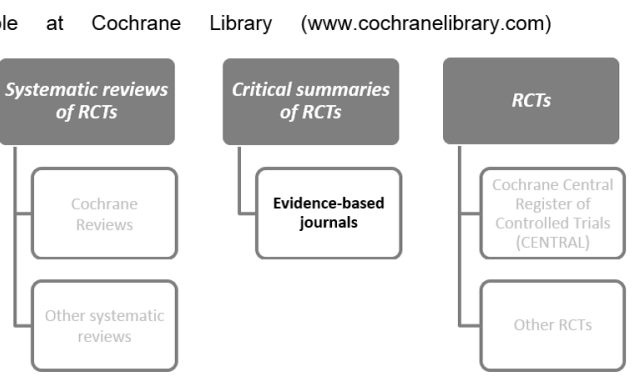

C) In bold: available at Evidence-based Dentistry (www.nature.com/ebd) and Journal of Evidence-based Dental Practice (www.jebdp.com)

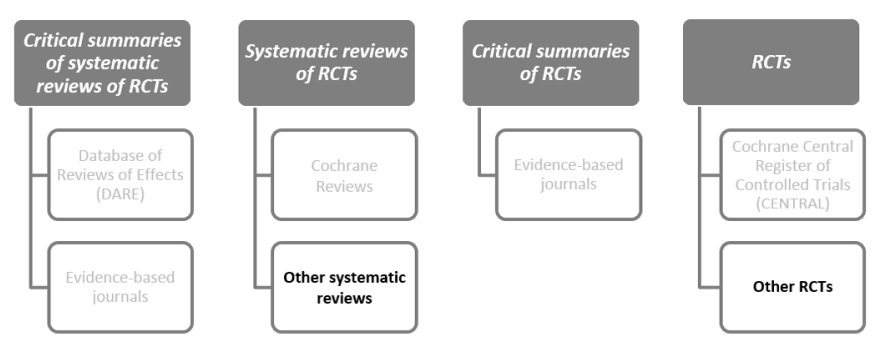

D) In bold: available at Pubmed/Clinical Queries (www.ncbi.nlm.nih.gov/pubmed/clinical)

Figure 1. Description of the search strategy and where to find the publications in each step.

\section{FINAL COMMENTS}

Dental students, professors and clinicians may question as how to proceed in specific clinical situations. The effectiveness of interventions may change over time, especially when RCTs are implemented in areas where evidence was formerly based on observational data. Therefore, it is expected that they will not have all the best answers straight away. On the other hand, clinical decisions cannot be postponed until new research is made; dental education and clinical practice demand prompt action. Thus, evidence consumers should look for the current best answer as efficiently as possible [3].

Some challenges are expected in the search for the current best answer. Firstly, textbooks, traditional sources of information, may be outdated and are considered inappropriate sources to answer questions regarding the effectiveness of health interventions. Secondly, the increasing number of articles makes it difficult to keep up-to-date with the latest findings [6]. Thirdly, industry funding and publication bias threaten the validity and availability of the evidence [3]. Lastly, evidence consumers may lack specific training to critically appraise the scientific evidence [2].

In recent years, clinical practice guidelines have increasingly become more evidence-based, as illustrated by those available at the ADA-EBD website (ebd.ada. org), but still many others have not. It has been shown that even so called "evidence based guidelines" may not really be evidence-based [7]. In addition, guidelines are supposed to make recommendations according to specific local circumstances. For these reasons guidelines were not included in the search strategy we are proposing. The aim of our search strategy is different from the aim of a practice guideline; we aim to facilitate evidence consumers globally to find the best evidence, while the guideline aims to make local recommendations about a clinical conduct. Thus, when evidence consumers find high quality evidence about a specific intervention using our search strategy, they will not necessarily strongly recommend it, as for that they need to consider, among other issues, the local prevalence and severity of the disease and the values and preferences of patients in their community.

Using search strategies such as the one proposed in this paper can enhance evidence consumers' ability to retrieve evidence that is important to dental education, clinical practice and delivery of oral health care. All databases described previously are valuable resources. The challenge is to be able to use them rationally and systematically. This paper offers an opportunity for doing so. There are other electronic resources available, but those tend to be less focused on oral health and dentistry, or would mostly repeat the evidence obtained through the system described in our paper. 


\section{Collaborators}

$P$ NADANOVSKY was responsible for the conception of the study. P NADANOVSKY and APP SANTOS were responsible for the design of the study, critical review of relevant intellectual content and article writing.

\section{REFERENCES}

1. Higgins JPT, Green S. Cochrane handbook for systematic reviews of interventions [cited 2017 Mar 20]. Available from: <http:// handbook.cochrane.org>.

2. Haynes RB. Acquiring the evidence: how to find current best evidence and have current best evidence find us. In: Straus SE, Glasziou P, Richardson WS, Haynes RB. Evidence-based medicine: how to practice and teach it. 4th ed. Oxford: Churchill Livingstone Elsevier; 2011.

3. Gray M. Finding good-quality evidence. In: Gray M. Evidencebased healthcare and public health. How to make decisions about health services and public health. 3rd ed. Oxford: Churchill Livingstone Elsevier; 2009.
4. Wilczynski NL, McKibbon KA, Walter SD, Garg AX, Haynes RB. MEDLINE clinical queries are robust when searching in recent publishing years. J Am Med Inform Assoc 2013;20(2):363-368. doi: 10.1136/amiajnl-2012-001075

5. McKibbon KA, Lokker C, Keepanasseril A, Wilczynski NL, Haynes RB. Net Improvement of Correct Answers to Therapy Questions After PubMed Searches: Pre/Post Comparison. J Med Internet Res 2013;15(11):e243. doi: 10.2196/jmir.2572

6. Bastian H, Glasziou P, Chalmers I. Seventy-five trials and eleven systematic reviews a day: how will we ever keep up? PLoS Med. 2010 Sep 21;7(9):e1000326. doi: 10.1371/journal. pmed.1000326

7. McAlister FA, van Diepen S, Padwal RS, Johnson JA, Majumdar SR. How evidence-based are the recommendations in evidencebased guidelines? PLoS Med. 2007;4: e250. doi: 10.1371/ journal.pmed.0040250
Received on: 8/5/2017

Final version resubmitted on: 12/6/2017

Approved on: 7/7/2017 